\title{
Analysis of Factors that Determine Inclusion of LULUCF into Realisation of EU Climate Policy Objectives 2021-2030 in the Non-ETS Sectors
}

* Institute of Environmental Protection - National Research Institute / The National Centre for Emissions Management;

e-mail: Zbyszko.Pisarski@kobize.pl

Keywords:

LULUCF, non-ETS, non-ETS sectors, GHG, removals, flexibility mechanisms

\begin{abstract}
Starting in 2021, Poland's emission reduction target for 2030, in the sectors not covered by the European Union Emissions Trading System (EU ETS) is $-7 \%$ compared to the emissions level in the non-ETS sectors in 2005. This is a big change in comparison with the target for the period of 2013-2020, which assumed potential emissions increase relative to the same baseline and was $+14 \%$ by 2020 . In order to cope with the need to make a much greater reduction effort, Poland will likely need to use flexibility mechanisms to support achieving the more ambitious target.

One the possible mechanism is the use of removals to cover likely excesses of annual non-ETS emissions through an additional individual limit on the number of removals generated in the land-use, land-use change and forestry (LULUCF) sector. However, this possibility is conditional on a range of factors associated with emission inventory and reporting, legal regulations and accounting procedures.

The present study addresses these factors in detail and highlights the linkages between them. It provides a comprehensive cross-cutting analysis of the issue and gives an insight into the scattered legal regulations in relation to the discussed subject. In conceivably straightforward ways, there are described the specific concepts and processes depicting the inclusion of removals in accounting to meet the reduction target in the non-ETS. The article points out the potential opportunities for Poland to comply with the obligations imposed by EU regulations.
\end{abstract}

(c) IOŚ-PIB

\section{INTRODUCTION}

Member States of the EU are obliged to meet designated limits for greenhouse gas (GHG) emissions not covered by the EU ETS, compliant with Regulation 2018/842 of the European Parliament and of the Council of 30 May 2018 on binding annual greenhouse gas emission reductions by Member States from 2021 to 2030 contributing to climate action to meet commitments under the Paris Agreement and amending Regulation 525/2013, referred to as the Effort Sharing Regulation (ESR).

The ESR replaced the Effort Sharing Decision (ESD) [Decision 406/2009/EC of the European Parliament and of the Council], and currently (since 2021) covers all GHG emissions included in the EU's target for emissions reductions in the sectors not covered by the EU ETS (nonETS). It aims at achieving by Member States the non-
ETS reduction target $-30 \%$ compared to 2005 . Now, the individual reduction target for Poland by 2030 is $-7 \%$ in relation to the level of non-ETS emissions in 2005. This is a substantial change when compared to the target under the ESD, which was effective for 2013-2020 and then $+14 \%$ against the same baseline (2005); that is, assumed potential increase in emissions. The current state of play generates a necessity to make a much greater effort by Poland to meet ambitious reduction target by 2030 and likely to reach for flexibility mechanisms.

The aim of the present study was to explore the possibilities of using Poland's accounted removals to cover possible excess of the annual emission limit in non-ETS sectors through an additional individual limit of removal units (RMUs) generated in the LULUCF sector. Moreover, some focus was given to the main sinks in the LULUCF sector 
(such as forests) since they are directly influencing sectoral mitigation potential of climate change. Furthermore, forest ecosystems in Poland that are subject to forest management have excellent carbon sequestration potential [Rykowski K. et al., 2014; p. 294].

\section{LULUCF FLEXIBILITY}

Since 2021 onwards, emissions and removals from the LULUCF sector have been partially included in the emission reduction effort 2021-2030 through their inclusion in the ESR. The latter regards only a specific flexibility mechanism between the ESR and LULUCF, because as a rule, under Article 2(2) the ESR does not comprise emissions and removals from the LULUCF sector.

The partial inclusion of LULUCF is hereafter treated as a contractual term for the purposes of further analyses, taking into account that in the commitment period 20212030 , it will be possible to take account of removals up to a maximum of $280 \mathrm{Mt} \mathrm{CO}_{2 \text { eq }}$ for all Member States of the EU. The inclusion of the balance of LULUCF emissions and removals into EU climate policy directly resulted from the provisions of the Conclusions of the European Council of 23-24 October 2014. The paragraph $2.14^{1}$ of this document opened the path to establishing rules for the contribution of the LULUCF sector to the EU's emission reduction target, sanctioned by the Energy and Climate Package.

The partial inclusion of the LULUCF sector in a very limited scale is a compromise result of discussion and negotiation where an environmental integrity was a key issue among the opponents of the opening towards use of the LULUCF removals. Finally, the European Commission (EC) got the shape of the mechanism of the restricted and narrow flexibility, analysed within this study. An environmental consideration was a cornerstone of the concept, and it was in-depth investigated by Böttcher, $\mathrm{H}$. and Graichen, J., [2016], who reiterated their previous conviction of their former study [2015]: "In that paper we concluded that the LULUCF sector should be accounted for separately to not harm ambition in other sectors."

The partial inclusion of net removals from LULUCF in accounting for the non-ETS reduction target is defined in the ESR (Article 7). The LULUCF Regulation sets out how to determine the balance of emissions and removals (net removals) to serve in accounting for the non-ETS target. Both of these regulations have brought the LULUCF sector within the EU's climate policy implementation activities, as a result of a long-standing discussion on the subject, advocated in the aforementioned Council Conclusions of October 2014, and reflected in the Paris Agreement in 2015. 'However, to reach the ambition as formulated in the Paris Agreement, Member States need to go beyond an accounted "no-debit" target' [Böttcher et al., 2019] ('no-

1 '...Policy on how to include Land Use, Land Use Change and Forestry into the 2030 greenhouse gas mitigation framework will be established as soon as technical conditions allow and in any case before 2020'. debit' rule is explained further, as it refers to the Member States).

It is worth noting that the inclusion of removals in the mechanisms of the Paris Agreement was also pursued by Poland, principally to be able to use the potential of own forests as a sink.

In the context of the partial use of removals from LULUCF for the purposes of non-ETS accounting, of much importance there are relevant delegated acts issued by the EC, pursuant to the delegations contained in the abovementioned regulations. The delegated acts, issued in conformity with Article 7 of the ESR, extend the accounting mechanism for the non-ETS sectors set out in the ESR and LULUCF Regulation by including the categories: 'managed forest land' (the LULUCF Regulation, Article 8) and 'managed wetlands' (the LULUCF Regulation, Article 7). Including the category'managed forest land' in accounting is conditional on, inter alia, the adoption of forest reference levels (FRLs). FRLs are to be submitted by Member States to the EC as part of their National Forestry Accounting Plans, compliant with Article 8(8) or (9) of the LULUCF Regulation. These are to be binding through a delegated act (based on the delegation under Article 8(8) or (9) of the LULUCF Regulation). A Delegated Act on FRLs was published by the EC on 28 October 2020 (see Section 2) [Commission Delegated Regulation (EU) 2021/268].

The possibility of including net removals from LULUCF in accounting as stated in the ESR provides for a specific mechanism, which, although not explicitly referred to as 'flexibility' in the ESR, is treated as one. Hence, this specific relationship between LULUCF and the ESR is referred to as flexibility from LULUCF.

As described above, accounting for emissions and removals in the LULUCF sector is governed by the LULUCF Regulation, whereas flexibility from LULUCF under the ESR, and its quantitative scope, are defined in the ESR Regulation (Article 7: Additional use of up to 280 million net removals from $\left.L U L U C F^{8}\right)$. The very wording in the title of Article 7 shows that in the commitment period 2021-2030, LULUCF is included in the accounting for a limited amount of a maximum of $\mathbf{2 8 0}$ million net removals. This amount is intended to be shared among all Member States, after a given Member State benefiting from the mechanism has cumulatively met all the conditions indicated in Article $7(1)$. In addition, a possibility to use part of the removals from a considered Member State's LULUCF sector is limited by an individual limit set out in Annex III to the ESR. It is worth noting at this point that the overall pool will be reduced in connection with Brexit, amounting for the EU27 only to 262 million $\mathrm{COO}_{2 \text { eq' }}$, but without affecting the limits falling on individual Member States. The limit for Poland amounts for 21.7 million $\mathrm{tCO}_{2 \text { eq }}$.

In view of the above, the possibility of limited use of RMUs has a supporting role in meeting a Member State's own reduction target as regards the non-ETS sectors. This mechanism would be intended to incentivise additional reduction efforts and activities in the LULUCF sector, rather than replace or undermine the reduction efforts in the 
ESR sectors. As Böttcher [Böttcher et al., 2019] observes 'flexibilities can potentially contribute to increasing incentives for Member States in implementing measures in all sectors and helps them achieving compliance with the regulations.' Therefore, the flexibility should be understood as an additional possibility rather than full integration of LULUCF and the ESR.

It is important to note that the LULUCF flexibility can also constitute a potential source of deficit in accounting for emissions under the ESR. This will occur if the combined accounting of emissions and removals in the LULUCF sector shows an excess of emissions (net emissions). The resulting deficit in removals will then be covered by allocating annual emission allowances in the ESR, which translates into decreasing the annual emission allocation (AEA) units available for the use in the ESR. In case a given Member State does not carry out own balancing with this regard, the Union Registry will automatically do so in a forced manner. This is the 'other side' of flexibility between the LULUCF sector and the ESR, and it arises from the adopted principle that LULUCF must be a net sink. This principle is referred to as 'no debit' rule. It is worth mentioning that flexibility from LULUCF requires various qualitative conditions to be met and is subject to a strict quantitative limit. Such a limitation is not present in the 'no debit' rule, which means that after exploitation of existing flexibilities, a total removal deficit in the LULUCF sector must be covered with the use of AEAs under the ESR.

On the other hand, it is also worth noting that 'This provision allows for offsetting of fossil fuel emissions with forestry credits. It is also problematic as enhanced ESD efforts would allow for increased harvesting of forests' [Fern, 2018]. Such a criticism comes from the non-governmental organizations' (NGO) side and calls for more stringent rules protecting LULUCF sector, regardless of the non-ETS compliance.

\subsection{Terms and conditions for making use of flexibility between LULUCF and the ESR [Article 7(1)(a-e)]}

1) The key criterion to be met in order to use flexibility by means of the units derived from removals in the LULUCF sector concerns the situation where the annual emission caps are exceeded, that is, when there occurs a shortfall of AEAs. The shortfall should not only result from exceeding the limit for a given year, but also from taking into account the carry-over of any surplus from previous years. This means that, firstly, all AEAs should be used cumulatively; second, and only when they are not there, the remaining shortfall can be accounted for through LULUCF flexibility - ESR, Article 7(1).

2) According to Article 7(1) of the ESR, only emissions and removals from the following combined categories can qualify for accounting under LULUCF flexibility: deforested land, afforested land (Article 6 of the LULUCF Regulation), managed cropland and managed grassland (Article 7 of the LULUCF Regulation) in the Member State considered, understood in the manner laid down in Article 2 of the LULUCF Regulation. This article specifies the categories which may accounted within LULUCF and allows optional inclusion of the 'managed wetlands' category.

3) At present, flexibility associated with the listed above LULUCF categories, covers only a fragment of the sector. As so far, it has not been possible to apply for recognition and accounting of the net balance of GHG emissions and removals for 'managed forest land', that would allow the possibility of the substitution effect (carbon accumulation) of Harvested Wood Products (HWP). As said by the EC, both the category 'managed forest land' and HWP show high uncertainty, need agreed baselines, and indicate a wide range of variability [European Commission, 2016, Impact Assessment - LULUCF, p. 45]. The inclusion of net removals from the category 'managed forest land' as well as 'managed wetlands' will be only possible if the ESR is amended appropriately. Such an amendment is allowed under Article 7(2) of the ESR, but conditional on the adoption of separate EC delegated regulations addressing the issue of FRLs, compliant with Article $8(8)$ or $8(9)$ of the LULUCF Regulation, and also, including contribution of the category 'managed wetlands' in accounting for LULUCF.

4) On 28 October 2020, the Commission published a Delegated Regulation on FRL, compliant with Article 8(8) and Article 8(9) of the LULUCF Regulation, that entered into force on 22 February 2021. The adoption of this Delegated Regulation opened the formal way for including forest management (category 'managed forest land') in the flexibility from LULUCF. However, it should be noted that a full procedure for formal extension of flexibility with the removals from forested areas requires a further EC delegated regulation compliant with Article 7(2) of the ESR, which will broaden the list of removals by sinks, that can be used under Article 7(1) of the ESR.

5) The specific conditions of eligibility for accounting the excess of the allocated annual limits of emissions from LULUCF, that is, for making use of LULUCF flexibility, are set out in Article 7(1) of the ESR, paragraphs (a-e), and these are as follows:

(a) the total number of units to be used to account for emissions, corresponding to the eligible net removals, cannot exceed the limit that has been allocated to the Member State for the entire period 2021-2030, which is set out in Annex III to the ESR; the limit for Poland is 21.7 million units;

(b) the net removals to be accounted for are in excess of the balance of emissions and removals set out in Article 4 of the LULUCF Regulation; this means that only if the balance of removals in LULUCF exceeds its emissions can this option be exercised;

(c) the Member State considered has not acquired more net removals under the LULUCF Regulation from 
another Member State than it has transferred itself, which means enforcing the use of units from domestic activities rather than those purchased from other Member States;

(d) the Member State considered complies with the requirements of the LULUCF Regulation to ensure that adequate monitoring of the LULUCF sector is maintained to avoid the risk of a deterioration in the quality of procedures and prevent the threat to environmental integrity;

(e) the Member State considered has provided a description of the intended use of flexibility from LULUCF, that is, the intention to use flexibility compliant with Article 14 of the LULUCF Regulation, which requires reporting on this intention - Art. 14 (1).

\subsection{Terms and conditions for making use of LULUCF flexibility under the LULUCF Regulation}

1) As a general rule, the LULUCF Regulation requires that emissions and removals from the LULUCF sector are balanced and that removals are enhanced in the long-term perspective. This premise is articulated in the preamble (Recital 11) of the LULUCF Regulation, which obliges Member States 'to ensure that the overall LULUCF sector does not generate net emissions and contributes to the aim of enhancing sinks in the long-term. This principle is referred to as 'no debit' rule, meaning that the LULUCF sector as a whole cannot generate emissions ('carbon debits'), and its different categories should balance each other in terms of the balance of emissions and net removals, resulting in a net removal prevalence.

The aforesaid principle articulated in the preamble is explicitly stated in Article 4 of the LULUCF Regulation as an obligation for Member States: Article 4 Commitments. For the periods from 2021 to 2025 and from 2026 to 2030, taking into account the flexibilities provided for in Articles 12 and 13, each Member State shall ensure that emissions do not exceed removals, calculated as the sum of total emissions and total removals on its territory in all of the land accounting categories referred to in Article 2 combined, as accounted in accordance with this Regulation. As already mentioned, any emissions in excess of removals in the LULUCF sector will be covered by an appropriate number of AEAs from the allocation of annual emission limits under the ESR. In addition, there is an EU-wide aspect to the principle of maintaining the prevalence of removals over emissions from LULUCF. If the EU as a whole fails to demonstrate removals in the LULUCF sector, then no Member State will individually be able to make use of the so-called compensation defined in Article 13 of the LULUCF Regulation, which allows for partial coverage of possible net emissions from managed forest land (see Section 4).
2) The LULUCF Regulation also provides for flexibility to help Member States meet the requirements for accounting their potential emissions from the LULUCF sector. Thus, there exists not only the flexibility between LULUCF and the ESR, with covering possible removal deficits under the 'no debit' rule. This aspect is treated as the flexibility in the LULUCF Regulation, but then again there are also flexibilities within the accounting of the LULUCF sector itself, that is, the socalled 'general flexibility'. The latter is referred to in Article 12 of the Regulation, and the 'managed forest land flexibility' is articulated in Article 13. The use of the above-mentioned flexibilities is conditional on the fulfilment of monitoring requirements, and the failure to meet those will result in blocking flexibility operations in the Union Registry. Monitoring and reporting requirements are set out in Article 26 of the Governance Regulation and its Annex V (see Section 3).

3) General flexibility (as stated in Article 12) applies to the LULUCF sector as a whole and allows for partial accounting of emissions in LULUCF with AEAs. It also allows surplus removals to be transferred to another Member State, as well as permits the carry-over of own saved units from the five-year commitment period (2021-2025) to that of 2026-2030. The number of removals possible be transferred to another Member State or carried over to the subsequent five-year commitment period is reduced by the amount associated with the maximum flexibility from LULUCF under the ESR (for Poland: 21.7 million). Such a flexibility could be perceived as a stimulus towards greater efforts increasing a sink potential. The same opinion is reflected by Böttcher et al. [2019] who observes that 'Compared to previous rules, the LULUCF Regulation increases incentives for improving land management.' This statement is then developed some further: 'The flexibility offered by the Regulation is expected to motivate Member States that have problems with achieving ESR targets to invest into measures that increase removals in forestry' [Böttcher et al., 2019].

4) Another, separate flexibility was established for accounting of emissions and removals generated under the category 'managed forest land', which is set out in Article 13 of the LULUCF Regulation (flexibility for managed forest land). This flexibility refers to 'compensation' under specific conditions. First of all, it can only be exercised if, in LULUCF-wide accounts, total emissions exceed total removals. If the accounts of the category 'managed forest land' also shows net emissions prevalence, then the removal deficit from this category could be waged to the reference level (FRL) by compensation. At the same time, the size of the compensation is reduced by the limit specified in Annex VII to the LULUCF Regulation. For Poland, the limit is 22.5 million $\mathrm{CO}_{2 \mathrm{eq}}$ for the period 2021-2030, as specified in the Annex VII 'Maximum amount of compensation available under the managed 
forest land flexibility referred to in point (b) of Article 13(3). Additionally, the Member State considered is entitled to this capped compensation, if demonstrates appropriate action to enhance removals in forests, as part of a low-carbon development strategy, provided that in the accounting cycle, there occurs the excess of removals over emissions in the LULUCF sector across the $\mathrm{EU}$ as a whole. The fulfilment of this condition [Article 13(2)(b)], means the EU-wide implementation of the 'no debit' rule, which does not depend upon individual Member State, but upon all of them. It seems, however, that this type of restriction was introduced somewhat overly, because in the perspective of 2030, the EC predicts maintaining prevalence of net removals across the EU as a whole ${ }^{2}$. Thus, under Article 13(3)(a), each Member State will be able to benefit from compensation for any debits in the forestry sector if its emissions exceed removals from LULUCF, and there exists additional predominance of emissions in the category 'managed forest land'. The size of the debits will be calculated based on FRLs, established for Member States separately. An additional condition for getting compensation is the overall state of affairs in the EU, where the LULUCF sector as a whole must show the balance of net removals. The compensation for individual Member States has its separate limits (as indicated above, e.g. in the period 2021-2030, for Poland it is 22.5 million $\mathrm{CO}_{2 \text { eq }}$ ). In view of the specificity of the above conditions, it can be generalised that flexibility as regards 'managed forest land' has a 'corrective' character, allowing for partial accounting of a possible negative emission balance in this very category.

At this point, it is worth noting the relevance of FRLs ${ }^{3}$. FRLs determined for each Member State separately, are the

2 European Commission analyses four scenarios for the UE LULUCF removals in the 2030 perspective. The net removals are estimated as (million): 225, 260, 295 or 340. Impact Assessment 'Stepping up Europe's 2030 climate ambition', European Commission, September 2020, [Fig.10: $\mathrm{CO}_{2}$ emissions and removals in the LULUCF sector, page 62, Part 1].

3 Article 8 (8). Based on the proposed forest reference levels submitted by Member States, on the technical assessment carried out pursuant to paragraph 6 of this Article and, where applicable, on the revised proposed forest reference level submitted under paragraph 7 of this Article, the Commission shall adopt delegated acts in accordance with Article 16 amending Annex IV with a view to laying down the forest reference levels to be applied by the Member States for the periods from 2021 to 2025 and from 2026 to 2030.

Article 8 (9). If a Member State does not submit its forest reference level to the Commission by the dates specified in paragraph 3 of this Article and, where applicable, paragraph 7 of this Article, the Commission shall adopt delegated acts in accordance with Article 16 amending Annex IV with a view to laying down the forest reference level to be applied by that Member State for the period from 2021 to 2025 or from 2026 to 2030, based on any technical assessment carried out pursuant to paragraph 6 of this Article. arithmetic means of the hypothetical forecast scenario for removals in the category 'managed forest land'. The removals in this category reported for the commitment period 2021-2025 will be related to FRLs. Any surplus resulting from exceeding the minimum removals (determined by the FRL value) can be used under the ESR and the flexibility from LULUCF. Hence, FRLs determined in the EC delegated act for 2021-2025 [Commission Delegated Regulation (EU) 2021/268] plays a key role in the future accounting of emissions and removals from managed forest land, and thus from the whole LULUCF sector, and thus will - indirectly - influence the final accounting of emissions under ESR. Poland's FRL, determined for 20212025 is 28.4 million tons $\mathrm{CO}_{2 \mathrm{eq}}$ /year. This amount seems to be possible to achieve with a surplus, unless there occur adverse conditions affecting the current development of forest stands. Therefore, balancing emissions and removals in the managed forest land category over the first 5-year commitment period (2021-2025) provides an opportunity to show such net removals that the entire LULUCF sector meets the 'no debit' rule, and also generates some surplus, usable as flexibility from LULUCF to account for a part of potential deficits under the ESR.

It should be stressed that generally 'Regarding intensification in forest management, the LULUCF Regulation is much stricter than earlier rules' [Böttcher et al., 2019].

\section{MONITORING AND REPORTING PROCEDURES RELATED TO LULUCF FLEXIBILITY UNDER THE GOVERNANCE REGULATION}

Regulation on the Governance of the Energy Union and Climate Action (the Governance Regulation) [Regulation (EU) 2018/1999 of the European Parliament and of the Council], in force since 2021, has replaced the Monitoring and Reporting Mechanism (MMR) set out in Regulation 2013/525 - mechanism for monitoring and reporting GHG emissions and for reporting other information at the national and Union-level relevant to climate change (MMR Regulation) [Regulation (EU) 525/2013 of the European Parliament and of the Council]. The broad scope of the Governance Regulation leads, among others, to the integration and expansion of reporting related to information pertinent to the implementation of the ESR and LULUCF Regulations. This integration is carried out towards the inclusion of a range of additional information into the annual GHG inventory system, as a continuation of activities carried out under previous reporting obligations with respect to the MMR. The Governance Regulation obliges Member States to include in their long-term strategies the sector-specific reduction actions, including those in the LULUCF sector, with a view to increasing removals by sinks. The latter directly applies to the LULUCF sector (Article 15. Long-term strategies, item 4 (b).

For emissions and removals from LULUCF, Member States are to notify to the EC their preliminary and final national 
inventory data by 15 January and 15 March in 2027 and 2032, respectively. The data will serve to account for the LULUCF sector, and the preparation of the compliance report under Article 14 of the LULUCF Regulation.

Article 14 of the LULUCF Regulation indicates that compliance reports under Article 4 of the Regulation shall be submitted to the EC by 15 March 2027 (for the commitment period of 2021-2025), and by 15 March 2032 (2026-2030). Member States should ensure that emissions from the LULUCF sector do not exceed removals. This shall be calculated as the sum of total emissions and total removals within a Member State's territory combined over all LULUCF land accounting categories. The accounting compliance reports will include the balance of total emissions and total removals for the relevant years for each of the land accounting categories referred to in Article 2 of the LULUCF Regulation, using the accounting rules set out in this regulation. Such a report shall also include, if applicable, data on the intention to use flexibility referred to in Article 11 of the LULUCF Regulation (LULUCF transfers) and the volumes involved or data on the use of flexibility and the volumes involved. The LULUCF Regulation [Article 14(2)] enables the EC to carry out a comprehensive review of the reports.

The Governance Regulation combines the reporting obligations for transfers under the ESR flexibility and that from LULUCF, into a single provision that states that reports should include 'summary information on completed transfers pursuant to Article 5 of Regulation (EU) 2018/842 and Articles 12 and 13 of Regulation (EU) 2018/841 for the year X-1' (Annex V, Part 1, point f).

In view of the aforesaid reporting obligations, set out in the Governance Regulation with respect to LULUCF and related flexibility, the Member States are required to prepare and submit detailed annual reports to the EC. Report format and the scope of data/information required is set out in the Commission Implementing Regulation 2020/1208 (hereinafter: the Implementing Regulation of the Governance Regulation) [Commission Implementing Regulation (EU) 2020/1208]. Article 20 of the Implementing Regulation provides that the Member States shall report on transfers of RMUs carried out under flexibility from LULUCF, pursuant to Articles 12 and 13 of the LULUCF Regulation. The form of such a report is set out in Annex XVI of the Governance Implementation Regulation. The annex, in the form of a table, collects detailed information on transfers made in each year under flexibility from LULUCF. The required information includes not only the volume of transfers and their recipients, but also the price of the units. As explained by the EC, the individual unit prices reported shall not be disclosed, but a range shall be given (from minimum to maximum), only after proper compilation of data provided by Member States: 'individual prices reported on concluded transfers will not be disclosed, while the range of prices paid per unit, i.e. the lowest and the highest price across all transactions reported by Member States, should be made available' (Recital 8 of the Implementing Regulation of the Governance Regulation).
The intention to use LULUCF flexibility, under Article 7 of the ESR, should be notified by Member States in compliance with Article 22 of the Implementing Regulation of the Governance Regulation, in the format set out in Table 2 of Annex XVIII to this Regulation. The information required relates to the number and volumes of planned transfers, which Member States intend to account for to meet their obligations under the ESR with the use of LULUCF flexibility. At the same time, the Governance Regulation [Article 30(2)] requires Member States to provide further information on their intention to use LULUCF flexibility, with respect to removal amounts anticipated to be accounted for under this mechanism, as well about policies and measures planned to ensure that LULUCF does not bring about net emissions ('no debit'). This information should be included in the National Energy and Climate Plan (Article 30 (2): 'A Member State that intends to use the flexibility pursuant to Article 7 of Regulation (EU) 2018/842 shall, as that information becomes available, include in the integrated national energy and climate plan the level of intended use and the planned policies and measures to fulfil the requirements laid down in Article 4 of Regulation (EU) 2018/841 for the period from 2021 to 2030'.

In 2027 and then in 2032, the EC will submit the reports on total EU emissions and total EU removals of GHGs for each of the LULUCF accounting categories referred to in Article 2 of the LULUCF Regulation, for the commitment periods 2021-2025 and 2026-2030. The reports will depict total EU emissions and total EU removals for a given five-year period minus five times the EU's average annual emissions and removals in the period 2000-2009.

\subsection{Accounting for flexibility-related emissions from LULUCF - the role of the registry}

In the period 2021-2030, GHG emissions reporting is to be done annually, whereas accounting for emissions in the LULUCF and ESR sectors is to be carried out just twice, split into two five-year accounting periods, 20212025 and 2026-2030. The change from annual to fiveyear accounting is explained by the EC in the Impact Assessment (LULUCF) ${ }^{4}$ in terms of significant reduction of administrative costs (approximately 50-60\% savings to the EC), as well as harmonisation with future reviews under the Paris Agreement. For the Member State, this means that accounting procedures will be postponed and accumulated every five years, while annual reporting will continue as usual.

The five-year accounting periods, defined in Article 9 of the ESR Regulation, coincide with the deadlines for balancing emissions and removals in the LULUCF sector under Article 14 of the LULUCF Regulation. Thus, the accounting for the ESR and LULUCF sectors will take place in 2027 (for the five-year period 2021-2025) and in 2032

4 Impact Assessment (LULUCF), page 81 and 82. 
(five-year period 2026-2030). The detailed schedule is set out in the Governance Regulation in Article 38(4), (5) and (6), according to which the following sequence of events is to take place in 2027 (and then in 2032):

1) Issuance of an implementing act by the EC, setting emission volumes in the ESR and LULUCF sectors;

2) A period of 4 months to account for the 5 -year balance of emissions and removals from the LULUCF sector, including flexibilities, such as potential transfers (2021-2025 or 2026-2030);

3) A period of 2 months to account for the year 2021 in the ESR (2026);

4) A period of 1 month to account for the year 2022 in the ESR (2027);

5) A period of 1 month to account for the year 2023 in the ESR (2028);

6) A period of 1 month to account for the year 2024 in the ESR (2029);

7) A period of 1 month to account for the year 2025 in the ESR (2030).

The timeline outlined above covers a total of 10 months. Central to this timetable is the EC implementing decision (see in Section 1), upon issuance of which the formal process of accounting for emissions in the 5-year commitment periods will begin. It is expected that the EC will issue the decision after the inventory review, which is to be done in the second half of 2027 (and then in 2032). Accordingly, the 10-month accounting cycle will likely end in the second half of 2028 (then in 2033).

Accounting for 2021-2030 as a whole (two 5-year periods) will mean an accumulation of compliance procedures. First of all, the commitment periods, will comprise as many as 5 years, not 1 year, as it has been so far under the ESD. The baseline for the ESR sector in each year may be different, assuming in theory one of three possibilities, that is, full compliance of emissions with the annual limit, or exceeding the limit (i.e. deficit of AEAs), or not using the limit (i.e. surplus of AEAs). Each year will have to be accounted for separately, which will be done by applicable operations carried out in the Union Registry, taking into account flexibilities (i.e. borrowing, banking and transfers). However, the starting position of the 5-year accounting period will be determined by the LULUCF balance sheet, consistent with the principle'no debit'. Hence, it is essential that there is no removals deficit in the LULUCF sector, at either a national or EU level and that a deficit does not cause an additional strain at the outset of accounting. On the other hand, a potential surplus of removals can help to account for individual years in the ESR, which is why a positive LULUCF accounting balance is so important. The aforesaid accounting as well as application of flexibility from LULUCF in the ESR will take place in the Union Registry. For this purpose, specific LULUCF accounts will be created in addition to the ESR accounts, for each year in the period 2021-2030. These will balance the removals and emissions of all the LULUCF categories, done for the 5 -year period being accounted for. The resulting balance for LULUCF can be negative, zero or positive. If there is a removal deficit, it will then be necessary to balance the missing difference with flexibility from LULUCF, that is, transfers from other Member States and/or their own AEA units, compliant with the 'no debit' rule. If emissions and removals are balanced, the LULUCF account will be zero, and no further operations in the Registry will be possible, as the account will be balanced. Yet, if there is an excess of removals over LULUCF emissions, the amount of the excess can be transferred to the relevant ESR account of the Member State in the form of specific units, that is, land mitigation units (LMUs) $\left[1 \mathrm{LMU}=1\right.$ tonne $\mathrm{CO}_{2 \text { eq }}$. Making use of these units will only be possible to carry forward the surplus to the second 5-year commitment period and to use flexibilities such as buy/sell (international trading), as well as in the accounting for emissions under the ESR, which, as discussed earlier, have their own quantitative and qualitative limitations, including the condition of reporting the planned use of flexibilities from LULUCF. The registry will be prepared to ensure that the conditions are met, and transactions not meeting all the criteria will be inaccessible (any non-transferred or unused LMUs will be automatically deleted).

An additional flexibility while accounting emissions from the 'managed forest land' category is the abovementioned 'compensation'. The Union Registry will allow for appropriate application of the mechanism related to the compensation through the use of additional specific accounting units, that is, 'managed forest land flexibility allocations' (MFLFAs) [1 MFLFA = 1 tonne $\mathrm{CO}_{2 \text { eq }}$. These will be used exclusively to implement the flexibility mechanism associated with the 'managed forest land' category. The units will only be 'created' in the LULUCF account if a given Member State can make use of them, that is, if it is eligible for compensation. The use of MFLFA will be conditional upon the LULUCF balance for the EU as a whole showing net removal prevalence. The registry will also 'check' whether the Member State considered is eligible to use the flexibility by fulfilling the condition of including in its long-term strategy a description of relevant activities that enhance removals in forests.

The procedures foreseen in the Union Registry also include the so-called compliance forcing, that is, ensuring that LULUCF accounts are balanced by the central administrator. If the Member State who uses (or not) the flexibility, still has a deficit in its LULUCF account, the Union Registry (central administrator) will make pertinent forced operations, and balance the account with AEAs, taken in equal amounts from each year of the relevant 5-year accounting period. Moreover, the failure to meet the monitoring conditions for emissions and removals in the LULUCF sector will result in the (temporary) blocking of the ability to execute transactions in the accounts, preventing the use of flexibilities such as relocations or transfers of LMUs. 


\subsection{The Union Registry procedures are as follows}

\section{1) Entering data on LULUCF}

The first step of accounting for the LULUCF sector in the registry will be to enter appropriate data on LULUCF emissions and removals. In this context, once the data on GHG emissions for the 5-year periods (verified in 2027 and 2032) are available, the central administrator will register in Member State's LULUCF compliance account the emissions and removals for each land accounting category referred to in Article 2 of the LULUCF Regulation. The central administrator will also record the sum of total emissions and removals in all the LULUCF accounting categories, overall in the Member States.

\section{2) Calculation of the balance for Member States and the EU's compliance accounts related to LULUCF}

After entering pertinent LULUCF data, the central administrator will ensure that the Union Registry calculates the balance of Member States' accounts and the EU LULUCF compliance account. This is done by subtracting the total emissions in the respective LULUCF compliance account from the total removals in the same LULUCF compliance account.

\section{3) Creation of LMUs}

Once the LULUCF compliance balance is positive for a given Member State, the central administrator will create a number of LMUs in the LULUCF account of that Member State, corresponding to the number of excess removals. LMUs shall be eligible for transfer to other LULUCF compliance accounts (under the conditions set out in Articles 11 and 12 of the LULUCF Regulation) as well as for the use in the ESR under flexibility from LULUCF.

\section{4) Transfer of LMUs under the LULUCF flexibility}

The transfer of LMUs for use in the ESR under flexibility from LULUCF takes place in the Union Registry in conformity with the rules set out in Article 59k of the EC Delegated Regulation $2019 / 1124^{5}$. The regulation plainly defines

5 LMU transfers shall not be carried out in any of the following cases [Commission Delegated Regulation (EU) 2019/1124]:

a) the requested amount exceeds the available quantity of LMUs eligible for transfers into the ESR Compliance Account pursuant to Article 59x or the remaining amount;

b) the requested amount exceeds the available amount according to Annex III to Regulation (EU) 2018/842 or the remaining amount; c) the requested amount exceeds the quantity of the emissions for the given year less the quantity of AEAs for the given year as set out in Article 10(2) of Regulation (EU) 2018/842 and the decisions adopted pursuant to Article 4(3) and Article 10 of that regulation, and less the sum of all the AEAs banked from previous years to the current or any following year pursuant to Article 59j of this regulation;

d) that Member State has not submitted its report in accordance with the second subparagraph of Article $7(1)$ of Regulation (EU) No $525 / 2013$ on its intention to use of the flexibility set out in Article 7 of Regulation (EU) 2018/842; the way of allocating LMUs between the LULUCF and ESR accounts of a given Member State. The number of LMUs allocated must be subject to the calculations described above that result from the balancing of emissions and removals, as well as from the extent of the balance in the accounts and that of the available limits of units defined in the relevant regulations. In addition, it is necessary to comply with the conditions for monitoring and reporting of emissions and removals from LULUCF set out in the LULUCF Regulation and to submit a report on the intention to use flexibility from LULUCF under Article 7 of the ESR. It should also be clarified that AEA units are to be fully used at first, and only when these run out, LMUs can be (possibly) used.

\section{NATIONAL FORESTRY ACCOUNTING PLAN}

Under the LULUCF Regulation, GHG emissions and removals from the category 'managed forest land' in each Member State will be accounted for against their FRL. It represents an appropriate projected baseline of expected emissions and removals associated with forest land in a given commitment period, namely 2021-2025 and 20262030.

According to Article 8(3) of the LULUCF Regulation, Member States should submit to the EC their national forest accounting plans, including a proposed FRL, by 31 December 2018 - for the period 2021-2025 and by 30 June 2023 for the period 2026-2030. National forest accounting plans constitute the tool for the Member States, as they enable to submit to the EC proposed FRL for own managed forest areas. Article 8(5) of the LULUCF Regulation states that the forest reference level shall be based on the continuation of sustainable forest management practice, as documented in the period from 2000 to 2009 with regard to dynamic age-related forest characteristics in national forests, using the best available data' [Regulation (EU) 2018/841 of the European Parliament and of the Council].

In addition, the LULUCF Regulation establishes that, following verification by the EC of reports submitted under Article 8(3), in accordance with Article 8(7), Member States shall submit to the EC their revised (on the basis of expert's group recommendations) reference levels by 31 December 2019 - for the years 2021-2025. The EC will adopt delegated acts in compliance with Article 16 of the LULUCF Regulation amending Annex IV, to set the

e) that Member State has not complied with the Regulation (EU) 2018/841;

f) the transfer is initiated before the calculation of the balance of the LULUCF Compliance Account of that MS or after the determination of the compliance status figure for the given compliance period pursuant to Articles 59u and 59za; $(\mathrm{g})$ the transfer is initiated before the calculation of the balance of the ESR Compliance Account of that MS or after the determination of the compliance status figure for the given year. 
reference levels to be applied by Member States in the commitment periods 2021-2025 and 2026-2030. This will be done on the basis of the proposed FRLs submitted by the Member States, the technical assessment carried out by the EC pursuant to Article 8(6) of the LULUCF Regulation and (where applicable) the revised proposed reference levels submitted pursuant to Article 8(7) of the LULUCF Regulation.

If a given Member State has not submitted its reference level by the dates laid down in Article 8(3) and, where applicable, Article 8(7), the EC may establish such a level for the Member State concerned. For that purpose, the EC may undertake any technical evaluation in accordance with Article 8(6). The reference level will be established by the $\mathrm{EC}$ in a delegated act amending Annex IV to specify the reference level [Article 8(9)], to be applied by the Member State concerned for the years 2021-2025 and 2026-2030. In compliance with Article $8(8)$ or (9) of the LULUCF Regulation, in October 2020, the EC amended the existing LULUCF legislation with a delegated act setting FRLs that each country must apply between 2021 and 2025. The delegated act for the period 2026-2030 shall be adopted by 30 April 2025.

The delegated act recapitulates the initiated in 2018 process of establishing a baseline for individual Member States. In addition to the FRL values, the act includes a characterisation of the process of preparing, submitting and reviewing the reference levels for managed forests. The process started with consultations between the EC and Member States ${ }^{6}$. Subsequently, on behalf of the EC, the IASA-ICF-AETHER consortium developed guidelines on how to set reference levels. In the next step, each Member State, including Poland, developed a National Forest Accounting Plan ${ }^{7}$ and submitted it by 31 December 2018. In 2019, the Expert Group on LULUCF (EG LULUCF) worked on submitted National Forestry Accounting Plans. The EG included the representatives of the Member States and independent experts hired by the EC, as well as the representatives of NGOs and interested observers drawn from NGOs that volunteered to participate in the process. The EG reviewed the submitted reports, and in June 2019, issued technical recommendations for upgrading the plans. By the end of 2019, each Member State submitted their National Forestry Accounting Plans with revised FRL values, which were then reviewed just by the experts hired by the EC. Identified uncertainties or possible recalculations were discussed with the Member States through bilateral consultations, while a summary of the meetings was presented to the EG LULUCF for approval during a 2-day online meeting.

The National Forest Accounting Plan prepared by Poland, being an element of fulfilling obligations of the Member State of the EU, aimed at defining and characterizing

6 Poland organised a workshop on FRL determining at its Permanent Representative.

7 Polish Report: https://bip.mos.gov.pl/strategie-plany-programy/ krajowy-plan-rozliczen-dla-lesnictwa/ own FRL in accordance with the LULUCF Regulation. The document was elaborated under the aegis of the Ministry of Climate [2019] (then the Ministry of Climate and Environment), by the Working Group established for preparation of national plans related to accounting of emissions and removals of GHGs from forestry-related activities. During consultations with the EC, Poland was represented by the Ministry of Climate and Environment, supported by the institutions participating in the preparation of versions of the National Forest Accounting Plan (i.e. National Centre for Emissions Management KOBiZE, Forest Research Institute - IBL, General Directorate of the State Forests - DGLP, Bureau for Forest Management and Geodesy - BULiGL).

As a result of bilateral consultations with regard to national plans, the value of FRL for Poland was slightly modified. The subject of consultations with the EC was, among others, the issue of consistency of CBM CFS modelling with the GHG inventory. The Commission pointed out some inconsistency between the effects of modelling and inventory data for changes in carbon stocks in mineral soils, litter and deadwood. In the inventory, given the uncertainty of estimates in this area, an approach is used which assumes that these reservoirs are not a source of net emissions ${ }^{8}$. In terms of consideration of dead wood in FRL and inventories data, indicated inconstancy should be seen as result of utilisation of different reporting approaches applied while preparing relevant data. Following the provisions of Article 5 paragraph 4 of LULUCF Regulation, Poland considered quantitative effects of modelling carbon stock changes in dead wood pool while defining FRL. However, GHG's data as included in the recent inventories, as summited to the UNFCCC, is considering dead wood pool not a net source of GHG's emissions and are providing verifiable information that demonstrates that this unaccounted pool is not a net source of anthropogenic GHG emissions (Article 2e, Decision 2/CMP.8). Furthermore, given the uncertainty of estimates of carbon stock changes in litter pool, a similar approach has been applied in this area, which assumes that this reservoir is also not a source of net emissions ${ }^{9}$. During the consultations, the EC proposed to Poland as follows:

- use the arithmetic mean of the inventory data reported in CRF 4.A.1 for the years 2000-2009 for changes in carbon stocks in mineral soils in the category'managed

8 Information on which, if any, of the following pools - above-ground biomass, below-ground biomass, litter, deadwood and/or soil organic carbon - were not accounted for, together with verifiable information that demonstrates that these unaccounted pools were not a net source of anthropogenic GHG emissions (Article 2e, Decision 2/ CMP.8).

9 Information on which, if any, of the following pools - above-ground biomass, below-ground biomass, litter, deadwood and/or soil organic carbon - were not accounted for, together with verifiable information that demonstrates that these unaccounted pools were not a net source of anthropogenic GHG emissions (Article 2e, Decision 2/ CMP.8). 
forest land' (under the GHG inventory framework, the category equated with CRF 4.A.1);

- for changes in carbon stocks in litter and deadwood, use the inventory approach, that is, the assume that these reservoirs are not a source of net emissions (Article 2e of Dec. 2/CMP.8), and thus exclude them from the FRL determination process;

- for emissions from wildfires within the 'managed forest land' category (under the GHG inventory framework, the category equated with CRF 4.A.1), use the arithmetic mean of the inventory data reported in Table CRF 4.V, for CRF category 4.A.1 for the years 2000-2009.

The EC emphasised that these were temporary solutions and did not prejudge the effect of the final accounting for the 'managed forest land' category. Nonetheless, the individual provisional solutions may be verified (recalculated), and the effect of these recalculations may be reported in the form of the so-called technical adjustment (technical correction) of the reference level before the end of the first LULUCF commitment period (i.e. by 2027), or else earlier when the estimation methodology with a low level of uncertainty is available. It seems that this type of approach should not have a significant impact on the value of mitigation potential of 'managed forest land' [Böttcher, H., Reise, J., 2020]. In addition to the above, another essential aspect is the recalculations performed annually by the countries as part of the continuous process of improving their GHG inventories [Pilli et. al., 2016].

\section{CONCLUSIONS}

Emissions and removals from the LULUCF sector that are included in the 2021-2030 reduction effort are subject to multiple conditions associated with the national inventory, reporting, legislation and accounting. Besides, the balance of emissions and removals may be disturbed by unexpected changes in forest areas, resulting, for example, from natural disasters, catastrophic events, or perturbations in the existing intensity of forest stand use. The review of EU legal acts conducted in this study shows the complexity of including LULUCF in climate policy. The introduced law with regard to this sector comprises numerous regulations; therefore, one should be aware of their scope and interconnections. To summarise these relationships, there can be stated that the legislation acts provide an elaborate way to ensure that the LULUCF sector is not accounted for as one that can cause net emissions; in other words, the regulations introduce restrictive mechanisms that implement the 'no debit' rule. In this context, it is difficult to predict how the entire sector will actually be accounted for in the two 5-year commitment periods in 2021-2030. However, regardless of the evolution of removal potential of Poland's forestland, which under LULUCF flexibility could be partially used to cover the expected emissions overrun in the ESR, the considerations presented in this analysis indicate that proper application of flexibility will require attention and appropriate effort. Therefore, it will be necessary to meet the described requirements and criteria carefully in order to take advantage of this opportunity to the fullest extent possible.

As of early 2021, preliminary estimates of total net removals applied to evaluate Poland's potential ability to make use of the flexibility between LULUCF and the ESR showed the capability to fully use the removals limit to account for emissions in the ESR, that is, 21.7 million over the 2021-2030 period. Nonetheless, properly estimating this potential and making a robust assessment in the context of flexibility between LULUCF and the ESR will require further separate analyses. Taking into account the results of the present study, we can only conclude that Poland has a good chance of making full use of LULUCF flexibility.

\section{REFERENCES AND LEGAL ACTS}

Böttcher, H. and Graichen, J., 2015, Impacts of the EU 2030 climate target of including LULUCF in the climate and energy policy framework, Oeko-Institut. https:// www.oeko.de/oekodoc/2320/2015-491-en.pdf dostęp: 28.09.2021

Böttcher, H. and Graichen, J., 2016, Going beyond $40 \%$ - options to ensure LULUCF maintains the high environmental integrity of the EU climate and energy package, Oeko-Institut. https://www.oeko.de/ oekodoc/2541/2016-068-en.pdf dostęp: 28.09.2021

Böttcher, H. et al., 2019, EU LULUCF Regulation explained, Oeko-Institut. https://www.oeko.de/publikationen/ p-details/eu-lulucf-regulation-explained dostęp: 28.09.2021

Böttcher, H., Reise, J., 2020, The climate impact of forest and land management in the EU and the role of current reporting and accounting rules, An investigation into the incentives provided by LULUCF reporting and accounting and their implications, Briefing for ECF and Fern, Oeko-Institut. https://www.oeko.de/ fileadmin/oekodoc/Briefing-LULUCF-FERN.pdf dostęp: 28.09.2021

Fern, 2018, Fern's analysis of the EU's LULUCF Regulation. https://www.fern.org/fileadmin/uploads/ fern/Documents/Analysis $\% 20$ of $\% 20$ trilogue $\% 20$ outcome\%20on\%20LULUCF\%20Regulation_final_0. pdf dostęp: 28.09.2021

Ministry of Climate, 2019, National Forestry Accounting Plan, https://bip.mos.gov.pl/fileadmin/user_upload/ bip/strategie_plany_programy/Krajowy_Plan_ Rozliczen_dla_Lesnictwa/NFAP_2019_POLAND_ENG_ FINAL.pdf dostęp: 28.09.2021 
Paris Agreement, 12.12.2015 https://unfccc.int/sites/ default/files/english_paris_agreement.pdf dostęp: 28.09.2021

Pilli R., Grassi G., Kurz W.A., Viñas R.A., Guerrero N.H., 2016, Modelling forest carbon stock changes as affected by harvest and natural disturbances. I. Comparison with countries' estimates for forest management, Carbon Balance and Management 11(1) DOI: 10.1186/s13021016-0047-8.

Rykowski K. et al.2014, Materiały pierwszego panelu ekspertów w ramach prac nad Narodowym Programem Leśnym; Klimat; Lasy i drewno a zmiany klimatyczne: zagrożenia i szanse; Instytut Badawczy Leśnictwa; ISBN 978-83-62830-18-3.

\section{EUROPEAN LEGAL ACTS AND OTHER DOCUMENTS}

Commission Delegated Regulation (EU) 2019/1124 of 13 March 2019 amending Delegated Regulation (EU) $2019 / 1122$ as regards the functioning of the Union Registry under Regulation (EU) 2018/842 of the European Parliament and of the Council (EU L 177, 2.7.2019).

Commission Delegated Regulation (EU) 2021/268 of 28 October 2020 amending Annex IV to Regulation (EU) 2018/841 of the European Parliament and of the Council as regards the forest reference levels to be applied by the Member States for the period 2021-2025 (EU L 60/22, 22.2.2021).

Commission Implementing Regulation (EU) 2020/1208 of 7 August 2020 on structure, format, submission processes and review of information reported by Member States pursuant to Regulation (EU) 2018/1999 of the European Parliament and of the Council and repealing Commission Implementing Regulation (EU) No749/2014 (EU L 278, 26.8.2020).

Decision 406/2009/EC of the European Parliament and of the Council of 23 April 2009 on the effort of Member States to reduce their greenhouse gas emissions to meet the Community's greenhouse gas emission reduction commitments up to 2020 (EU L 140, 5.6.2009).

European Commission, 2016, Impact Assessment (LULUCF) - Commission Staff Working Document Impact Assessment Accompanying the document "Proposal for a regulation of the European Parliament and of the Council on the inclusion of greenhouse gas emission and removals from land use, land use change and forestry into 2030 climate and energy framework and amending Regulation No 525/2013 of the European Parliament and the Council on a mechanism for monitoring and reporting greenhouse gas emissions and other information relevant to climate change" (SWD(2016) 246 final).

European Commission, 2018, A Clean Planet for all, A European strategic long-term vision for a prosperous, modern, competitive and climate neutral economy, Communication from the Commission to the European
Parliament, the European Council, the Council, the European Economic and Social Committee, the Committee of the Regions and the European Investment Bank (COM(2018) 773 final).

European Commission, 2020a, Commission Staff Working Document Assessment of the National Forestry Accounting Plans Regulation (EU) 2018/841 of the European Parliament and of the Council on the inclusion of greenhouse gas emissions and removals from land use, land use change and forestry in the 2030 climate and energy framework, and amending Regulation(EU)No 525/2013 and Decision No 529/2013/ EU Accompanying the document Communication from the Commission to the European Parliament, the Council, the European Economic and Social Committee and the Committee of the Regions United in delivering the Energy Union and Climate Action - Setting the foundations for a successful clean energy Transition (SWD/2019/213 final).

European Commission, 2020b, A Farm to Fork Strategy for a fair healthy and environmentally-friendly food system, Communication from the Commission to the European Parliament, the Council, the European Economic and Social Committee and the Committee of the Regions (COM(2020) 381 final).

https://ec.europa.eu/info/sites/info/files/communicationannex-farm-fork-green-deal_en.pdf dostęp: 28.09.2021

European Commission, 2020c, Amendment of the Land Use, Land Use Change and Forestry Regulation Inception Impact Assessment, (EU) 2018/841. https:// ec.europa.eu/info/law/better-regulation/have-yoursay/initiatives/12657-Land-use-land-use-change-\&forestry-review-of-EU-rules_en dostęp: 28.09.2021

European Commission, 2020d, Stepping up Europe's 2030 climate ambition. Investing in a climate-neutral future for the benefit of our people. Impact Assessment accompanying the document Communication from the Commission to the European Parliament, the Council, the European Economic and Social Committee and the Committee of the Regions, Commission Staff Working Document (SWD(2020) 176 final).

European Council (23 and 24 October 2014), Conclusions on 2030 Climate and Energy Policy Framework, SN $79 / 14$

http://data.consilium.europa.eu/doc/document/ST-1692014-INIT/pl/pdf dostęp: 28.09.2021

FCCC/KP/CMP/2012/13/Add.1; Decision 2/CMP.8, Implications of the implementation of decisions 2/ CMP.7 to 5/CMP.7 on the previous decisions on methodological issues related to the Kyoto Protocol, including those relating to Articles 5, 7 and 8 of the Kyoto Protocol.

https://unfccc.int/resource/docs/2012/cmp8/eng/13a01. pdf\#page=14 dostęp: 28.09.2021

Regulation (EU) 525/2013 of the European Parliament and of the Council of 21 May 2013 on a mechanism for monitoring and reporting greenhouse gas emissions and for reporting other information at national and 
Union level relevant to climate change and repealing Decision No 280/2004/EC (EU L 165, 18.6.2013).

Regulation (EU) 2018/841 of the European Parliament and of the Council of 30 May 2018 on the inclusion of greenhouse gas emissions and removals from land use, land use change and forestry in the 2030 climate and energy framework, and amending Regulation (EU) No 525/2013 and Decision No 529/2013/EU (EU L 156, 19.6.2018).

Regulation (EU) 2018/842 of the European Parliament and of the Council of 30 May 2018 on binding annual greenhouse gas emission reductions by Member States from 2021 to 2030 contributing to climate action to meet commitments under the Paris Agreement and amending Regulation (EU) No 525/2013 (EU L 156, 19.6.2018).

Regulation (EU) 2018/1999 of the European Parliament and of the Council of 11 December 2018 on the Governance of the Energy Union and Climate Action, amending Regulations (EC) No 663/2009 and (EC) No 715/2009 of the European Parliament and of the Council, Directives 94/22/EC, 98/70/EC, 2009/31/EC, 2009/73/EC, 2010/31/EU, 2012/27/EU and 2013/30/ EU of the European Parliament and of the Council, Council Directives 2009/119/EC and (EU) 2015/652 and repealing Regulation (EU) No 525/2013 of the European Parliament and of the Council (EU L 328, 21.12.2018). 